\title{
UK Naval Dockyards Asbestosis Study: radiological methods in the surveillance of workers exposed to asbestos
}

\author{
G. SHEERS ${ }^{1}$, C. E. ROSSITER ${ }^{2}$, J. C. GILSON ${ }^{2}$, AND F. A. F. MACKENZIE
}

From the ${ }^{1}$ Plymouth General Hospital, the ${ }^{2}$ MRC Pneumoconiosis Unit, Llandough Hospital, Penarth, and the ${ }^{3}$ Royal Naval Hospital, Plymouth

ABSTRACT In a survey of the effects of exposure to asbestos in the UK Naval Dockyards, small- and large-film chest radiographs of 674 men have been examined. These films have been read under survey conditions by two readers using a simple screening classification, and also in a controlled trial by five readers using the full ILO U/C classification. Comparison between the reading methods showed a deficiency, independent of the size of film, of at least $30 \%$ in the detection of asbestosrelated radiographic abnormalities when the screening classification was used. For adequate diagnostic sensitivity the ILO U/C classification appears to be essential. There was a deficiency of $43 \%$ in significant abnormalities observed by a majority of readers in the small films when directly compared with large film readings. This deficiency could be reduced to $7 \%$ by using readings of the small films at any level of abnormality by any of the five readers. When the ILO U/C readings were related to the clinical diagnoses, the only abnormality missed was a small pleural plaque. Films with previously agreed coding were inserted at intervals during the reading trial and helped to maintain the consistency of reading. Right oblique views were taken for $1884 \mathrm{men}$, in addition to the fullsized postero-anterior view, but the contribution provided by this view proved insufficient to justify its use in large surveys. The cost of a survey when small films are used as a screening method is reduced to between one-third and one-half of the cost when large films are used, assuming that the abnormality rate is not more than $5 \%$. However, this cost advantage for small films is likely to be overtaken by the development of automatic large-film units. The radiation dose when small films are used is increased by a factor of about 20 , but is within the prescribed safety level. It is concluded that at least three readers should be involved, using the full ILO U/C classification. Small films may be of particular use in a large-scale survey, in which the abnormality rate is expected to be low, and which might otherwise be too expensive. A sensitive reading method and a high standard of film quality are essential factors in the use of this technique.

This report considers the methods used in the radiographic examination of a large working population for the purpose of detecting abnormalities related to asbestos exposure. The aims were to identify individuals at an early stage in the development of disease and to assess prevalence and attack rates in an exposed population. The first aim requires a high level of diagnostic sensitivity, and the second necessitates a constant standard. We have tried to achieve a satisfactory compromise between the requirements of these objectives and economy in time, expertise and costs.

Received for publication 28 September 1977 Accepted for publication 8 December 1977
The relative values of different reading methods, different film sizes and additional views are assessed on the basis of experience gained in a survey of 36714 dockyard workers and in a controlled reading trial of films of a smaller sample of 2040 men with a higher abnormality rate. The use of full-sized films and additional views in the examination of the individual subject is not in question.

\section{Methods}

POPULATION

The population studied included all male workers in the four main naval dockyards in the United Kingdom (Harries et al., 1976). From the total 
population in this survey a stratified sample was drawn, weighted in favour of those more heavily exposed. All registered asbestos workers were included irrespective of age. In the other occupational groups the sample was restricted to men aged 50-59 and consisted of about one in three men in occupations with intermittent exposure and one in 30 men in occupations with lesser or negligible risks. Ninety-five per cent of the men in this sample had clinical and pulmonary function examinations in addition to the chest radiograph, and for a representative subgroup of 674 men $(33 \%)$ the readings of both large and small films were available. These men were examined on both sizes of film because notification that they were members of the sample could not be completed until after the initial $100 \mathrm{~mm}$ radiographic survey had started.

The numbers examined and the abnormality rates in the total population and in the sample are shown in Table 1. These abnormality rates refer only to asbestos-related conditions considered to be of clinical significance after a full assessment based on occupational history, symptoms, signs and pulmonary function examinations in addition to fullsized chest radiographs including, in most cases, an oblique view.

Table 1 Populations and abnormality rates

\begin{tabular}{lc}
\hline Population & Statistics \\
\hline Total population & 36714 \\
Number examined & 28971 \\
Number with asbestos-related abnormality & 1487 \\
Asbestos-related abnormality rate & $5 \%$ \\
& 2040 \\
Group drawn for detailed studies & 1902 \\
Number examined on full-sized films & 281 \\
Number with asbestos-related abnormality & $15 \%$ \\
Asbestos-related abnormality rate & 674 \\
\hline
\end{tabular}

\section{RADIOGRAPHIC TECHNIQUES}

\section{Large films}

Most of the large films were taken by the mobile unit of the MRC Pneumoconiosis Unit using a Schoenander Plermobile generator capable of $90 \mathrm{kV}$ at $300 \mathrm{~mA}$ and $110 \mathrm{kV}$ at $200 \mathrm{~mA}$. Exposure times were controlled by a Siemens Iontomat. A Siemens rotating anode tube with a $2 \mathrm{~mm} \times 2 \mathrm{~mm}$ focal spot was linked to the chest stand at a distance

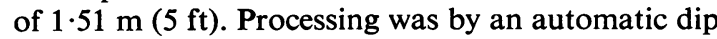
and lift processor. Film quality was controlled by comparison with a calibrated set using a standard step wedge. High definition screens for $400 \mathrm{~mm} \times$ $400 \mathrm{~mm}$ standard speed films were used.
Exposure factors were between 60 and $75 \mathrm{kV}$ at $300 \mathrm{~mA}$ with exposure 20 to $50 \mathrm{~mA}$ for average subjects. For very large subjects, $110 \mathrm{kV}$ at $200 \mathrm{~mA}$ was used with a wafer grid. In addition to the standard postero-anterior view, a right anterior oblique at $45^{\circ}$, requiring only slight adjustment of exposure factors, was taken (Mackenzie and Harries, 1970). In order to compare examination rates for a single view, a rate of 30 films per hour for the large film technique has been assumed.

\section{Small films}

These were all $100 \mathrm{~mm} \times 100 \mathrm{~mm}$ photofluorographs taken with an Odelca camera with phototimer. Most were taken by the Royal Naval mobile unit using a Watson R301 generator capable of $125 \mathrm{kV}$ at $300 \mathrm{~mA}$. The tube was a Dynamax $40 \mathrm{HD}$ with $2 \mathrm{~mm}$ focal spot, linked to the camera at a distance of $0.91 \mathrm{~m}$ $(3 \mathrm{ft}$ ). Exposure factors ranged from $84 \mathrm{kV}$ for the average subject to $100 \mathrm{kV}$ for large subjects, giving exposure times similar to those for large films. Most of the films were processed automatically in the Odelcamatic processor. An examination rate of 100 films per hour has been taken as the maximum for work of good quality and careful positioning.

\section{RADIOGRAPHIC CLASSIFICATION}

In the initial survey of the total dockyard population, small films were used and coded according to a simple screening classification which enabled suspected asbestos-related abnormalities to be separated from other diseases and from normals. The asbestosrelated abnormalities were scored as either pleural or parenchymal fibrosis. Pleural fibrosis was subdivided by extent (limited or extensive) and by calcification (present or absent). Parenchymal fibrosis was scored as either suspected or definite.

For the sample population, a slightly elaborated version of the full ILO U/C 1971 classification was used for the large films. This elaboration recorded width and extent of pleural abnormalities on each side separately and also separated plaques from diffuse thickening. Minimal pleural thickening was recorded as width ' $a$ ', but extent ' 0 '. Pleural calcification was also graded separately for each side. For the small films, the same classification was used with estimated sizes where required.

\section{READING METHODS}

All films were read by one reader* as soon as possible after examination, in order to detect abnormalities requiring urgent clinical action.

In the survey of the total population the films were subsequently read by two readers from a separate

*Surgeon Captain B. M. Goldsworthy. 
panel of four. $\dagger$ The films were read independently and a positive coding by either reader has been scored in the analyses. Reading the small films at this stage of the survey was simply to decide whether to recall or not for fuller examination. Large films from the sample population were read initially in the same way.

In the film reading using the ILO U/C 1971 classification (International Labour Office, 1972), the films were read concurrently by five readers $\ddagger$ in batches of equal numbers to a time-table designed to avoid the onset of fatigue. Before starting the main film reading, 45 selected films were read and agreement on coding was reached in subsequent discussion. These films were used as 'triggers' after approximately every ninth film, in order to improve the consistency of reading. Each trigger film was included four times so that the average time between readings of any one trigger film was three and a half days. Immediately after his classification of a trigger film the reader was told that it was one of these films and he was able to compare his reading with the agreed coding. These films were not usually recognised except for two with memorable peculiarities. The reading of the postero-anterior view was recorded in full before the examination of the oblique view.

Small films were read similarly, but without the use of triggers or oblique views. Judgement rather than measurement had to be used to assess the sizes of radiographic changes for classification.

Reading rates were slower when using oblique views but in a later trial using large postero-anterior views only, the rate averaged 40 films per hour. The small films were read faster at about 60 films per hour, partly because of the smaller area to be scanned and also the easier film handling.

Films were read in four equal batches per day. Each batch comprised 35-40 postero-anterior views together with the respective oblique views, and took 75-90 min to read. Clerks were used to complete the reading sheets and only $1 \%$ of the sheets had incomplete codings. No evidence of fatigue could be detected in a comparison between the readings of trigger films placed early in a batch and the readings of the same films placed towards the end of a batch.

\section{costs}

Expenditure is substantially reduced when small films are used. Among the minor items, floor space for storage is reduced by a factor of 45 , film costs

†Surgeon Captain F. A. F. Mackenzie; Dr G. Sheers; Surgeon Commanders P. G. Harries and K. P. S. Lumley.

$\ddagger D r$ J. C. Gilson, together with the above four readers. are reduced by a factor of nine, and chemicals by a factor of six. Film transport costs are reduced by a factor of five and envelopes are unnecessary. However, the major items are staff salaries and maintenance of buildings and vehicles: these two items alone account for $90 \%$ of the cost of producing a small film and for $80 \%$ of large film costs. Thus, the factors governing costs are throughput and the film reading rates, because the influence of costs of materials is submerged by these large overheads.

A ratio of approximately $3: 1$ between the costs for large and small films is a reasonable assessment when allowance is made for a slower than average examination rate in surveys designed to detect pneumoconiosis. If small films are used as a screening method, followed by recall for examination on large films when an abnormality is suspected, an additional cost must be allowed for the recall examination. Thus a recall rate of $10 \%$ would alter the ratio of costs for large and small films to $2 \cdot 2: 1$.

Assuming the cost of a small film examination to be about $£ 1$, the difference between the costs of using large and small films in this survey would be approximately $£ 55000$ ( $£ 85000$ for large films and $£ 30000$ for small films). Allowing for the recall procedure, the difference in expenditure would be reduced to $£ 46500$.

An indirect cost, which may be quite high, arises from the disturbance of industrial production caused by a radiographic survey. Again, this is related to the examination rate and is therefore reduced by the use of small films, but against this must be set the additional disturbance caused by the recall procedure.

\section{RADIATION DOSE}

A series of measurements of skin radiation dose has been made by $\mathrm{Dr}$ C. S. Bowring of the Department of Medical Physics of Plymouth General Hospital on 10 adult males for each radiographic technique, using thermoluminescent dosimetry with lithium fluoride discs. The discs were calibrated by comparison of their light output with the radiation measured by an ionisation chamber exposed simultaneously to the $x$-ray beam. For calibration, discs were placed on both sides of the ionisation chamber and, for measurement in the subjects, the discs were taped to the skin in the centre of the $x$-ray beam.

For the $100 \mathrm{~mm}$ photofluorograph the average dose was $220 \mathrm{mrad}$, range $95-315 \mathrm{mrad}$. For the standard postero-anterior chest radiograph, the average dose was $11 \mathrm{mrad}$, range $7-17 \mathrm{mrad}$. The dose for the $45^{\circ}$ oblique view was calculated from the exposure settings. Without the grid the dose was $20-25 \mathrm{mrad}$; with the grid the dose was increased to 40-45 mrad. For comparison, the dose for intravenous pyelography is about $3400 \mathrm{mrad}$. 


\section{Results}

REPEATABILITY OF FILM READING

Before evaluating the results of different methods of film reading, the standard of repeatability attained during the reading should be assessed. For the large films, this information can be obtained from the readings of the trigger films, as 90 pairs. During the reading of the small films there were no trigger films, but 72 films were fed back into the series so that assessment of intra-observer repeatability could be made. In the initial repeatability trials of the UICC/Cincinnati classification, on which the ILO $\mathrm{U} / \mathrm{C}$ classification is based, Rossiter (1972) reported the repeatability standardised to $30 \%$ abnormal films as was suggested by Ashford and Enterline (1966). This standardised repeatability index takes into account all deviations from complete agreement on classification for each feature and provides one means of comparing repeatability of different features, readers or surveys.

Table 2 compares this index, for the large and small films used in our survey, with the initial repeatability results. Throughout, as there is no evidence that the readings for any one reader were consistently less repeatable, only averages and ranges are presented. The readings of pleural thickening for both film sizes were perhaps somewhat less repeatable in this study than in the initial trials, whereas for pleural calcification and irregular small opacities the present readings were slightly more repeatable for large films, and rather more so for the small films. In the slightly modified ILO U/C classification used in the survey reported here, the lower limit for recording the extent of pleural thickening is set below that used in the UICC/ Cincinnati classification. Consequently there is more likelihood of disagreement on presence or absence of pleural thickening, leading to a lower figure for repeatability. Similarly, the apparently better repeatability of readings of the small films could arise because indefinite abnormalities may not be seen on small films so that the detection of abnormalities is much more a Yes/No process.

Table 3 Inter-observer variation*

\begin{tabular}{llrl}
\hline Feature & \multicolumn{2}{l}{ Range of prevalence rates } \\
\cline { 2 - 4 } & Large films & Small films & $\begin{array}{l}\text { Rossiter } \\
(1972)\end{array}$ \\
\hline $\begin{array}{l}\text { Pleural thickening extent } \\
\quad 1 \text { or more }\end{array}$ & $14 \%-30 \%$ & $14 \%-24 \%$ & $20 \%-36 \%$ \\
$\begin{array}{l}\text { Pleural calcification } \\
\text { grade 1 or more }\end{array}$ & $3 \%-4 \%$ & $3 \%-5 \%$ & $16 \%-22 \%$ \\
$\begin{array}{c}\text { Small irregular opacities } \\
\text { sub-category 0/1 or more }\end{array}$ & $8 \%-31 \%$ & $8 \%-19 \%$ & $20 \%-54 \%$ \\
\hline
\end{tabular}

* Range of prevalence rates of radiographic abnormality recorded by the five readers, and the range observed in the initial trials of the UICC/Cincinnati classification for six readers who had worked together (Rossiter, 1972).

INTER-OBSERVER VARIABILITY

Table 3 shows the range of prevalence rates, for the five readers, of pleural thickening, pleural calcification and small irregular opacities. These ranges are also compared with those for the six readers who used the UICC/Cincinnati classification in the survey of the Quebec chrysotile mining industry (Rossiter, 1972).

It is apparent that there are still inter-observer differences of the same order as those obtained in the initial trials of the classification. The differences appear to be less for the readings of the small films, possibly for the same reason as has been suggested to explain the better repeatability of these readings.

\section{SENSITIVITY}

In order to compare the overall results of different reading methods using different film sizes, a common

Table 2 Intra-observer repeatability expressed as percentage agreement standardised to $30 \%$ abnormal films. Comparison of readings by five readers of large and small films, and with the results of the initial repeatability trials of the UICC/Cincinnati Classification*

\begin{tabular}{|c|c|c|c|c|c|c|}
\hline \multirow[t]{3}{*}{ Feature } & & \multicolumn{5}{|c|}{ Percentage agreement standardised to $30 \%$ abnormal films } \\
\hline & & \multicolumn{2}{|c|}{ Large films } & \multicolumn{2}{|c|}{ Small films } & \multirow{2}{*}{$\begin{array}{l}\text { Rossiter (1972) } \\
\text { Average }\end{array}$} \\
\hline & & Average & Range & Average & Range & \\
\hline Pleural thickening & $\begin{array}{l}\text {-width } \\
\text {-extent }\end{array}$ & $\begin{array}{l}84 \cdot 9 \\
84 \cdot 8\end{array}$ & $\begin{array}{l}83-86 \\
82-87\end{array}$ & $\begin{array}{l}84 \cdot 5 \\
85 \cdot 3\end{array}$ & $\begin{array}{l}77-93 \\
73-91\end{array}$ & $86.9+$ \\
\hline Pleural calcification & -grade & $94 \cdot 2$ & $92-96$ & $98 \cdot 6$ & $97-100$ & $93 \cdot 5$ \\
\hline \multicolumn{2}{|c|}{$\begin{array}{r}\text { Small irregular opacities - type } \\
\text {-profusion }\end{array}$} & $\begin{array}{l}78 \cdot 7 \\
82 \cdot 5\end{array}$ & $\begin{array}{l}74-81 \\
79-86\end{array}$ & $\begin{array}{l}87 \cdot 3 \\
91 \cdot 0\end{array}$ & $\begin{array}{l}79-96 \\
79-99\end{array}$ & $\begin{array}{l}77 \cdot 8 \\
82 \cdot 1\end{array}$ \\
\hline
\end{tabular}

* Rossiter, 1972

† Grade of extent of pleural thickening only was recorded in the UICC/Cincinnati classification. 
Table 4 Comparisons of reading methods*

\begin{tabular}{|c|c|c|c|c|c|c|c|}
\hline & & & \multicolumn{3}{|c|}{$\begin{array}{l}\text { Large film reading positive at standard } \\
\text { level of abnormality } \dagger\end{array}$} & \multirow[t]{2}{*}{$\begin{array}{l}\text { Overall } \\
\text { agreement }\end{array}$} & \multirow{2}{*}{$\begin{array}{l}\text { Agreement among } \\
\text { films positive at } \\
\text { standard level }\end{array}$} \\
\hline & & & Yes & No & Total & & \\
\hline 1. & $\begin{array}{l}\text { Small films: positive } \\
\text { at standard level } \dagger\end{array}$ & $\begin{array}{l}\text { Yes } \\
\text { No }\end{array}$ & $\begin{array}{l}71 \\
54\end{array}$ & $\begin{array}{r}12 \\
537\end{array}$ & $\begin{array}{r}83 \\
591\end{array}$ & $.90 \cdot 2 \%$ & $56.8 \%$ \\
\hline 2. & $\begin{array}{l}\text { Small films: positive } \\
\text { at any level by } 3 \text { readers }\end{array}$ & $\begin{array}{l}\text { Yes } \\
\text { No }\end{array}$ & $\begin{array}{l}91 \\
34\end{array}$ & $\begin{array}{r}17 \\
532\end{array}$ & $\begin{array}{l}108 \\
566\end{array}$ & $92.4 \%$ & $72 \cdot 8 \%$ \\
\hline 3. & $\begin{array}{l}\text { Small films: positive } \\
\text { at any level by } 2 \text { readers }\end{array}$ & $\begin{array}{l}\text { Yes } \\
\text { No }\end{array}$ & $\begin{array}{r}100 \\
25\end{array}$ & $\begin{array}{r}21 \\
528\end{array}$ & $\begin{array}{l}121 \\
553\end{array}$ & $93.2 \%$ & $80.0 \%$ \\
\hline 4. & $\begin{array}{l}\text { Small films: positive } \\
\text { at any level by any reader }\end{array}$ & $\begin{array}{l}\text { Yes } \\
\text { No }\end{array}$ & $\begin{array}{r}116 \\
9\end{array}$ & $\begin{array}{r}22 \\
527\end{array}$ & $\begin{array}{l}138 \\
536\end{array}$ & $95.4 \%$ & $92.8 \%$ \\
\hline 5. & $\begin{array}{l}\text { Small films: positive } \\
\text { on screening reading }\end{array}$ & $\begin{array}{l}\text { Yes } \\
\text { No }\end{array}$ & $\begin{array}{l}80 \\
45\end{array}$ & $\begin{array}{r}43 \\
506\end{array}$ & $\begin{array}{l}123 \\
551\end{array}$ & $86.9 \%$ & $64.0 \%$ \\
\hline \multirow[t]{2}{*}{6.} & $\begin{array}{l}\text { Large films: positive } \\
\text { on screening reading }\end{array}$ & $\begin{array}{l}\text { Yes } \\
\text { No }\end{array}$ & $\begin{array}{l}87 \\
38\end{array}$ & $\begin{array}{r}57 \\
492\end{array}$ & $\begin{array}{l}144 \\
530\end{array}$ & \multirow[t]{2}{*}{$85.9 \%$} & \multirow[t]{2}{*}{$69 \cdot 6 \%$} \\
\hline & Total number of readings & & 125 & 549 & 674 & & \\
\hline
\end{tabular}

* Positive readings of large films at standard level of abnormality compared with ILO U/C readings of small films and with the screening readings of the large and small films.

†See Table 5 for definition of standard level of abnormality.

reference point has been set by defining a standard level of abnormality using the ILO U/C classification and large films. This standard level requires readings by at least three of the five readers and excludes categories of small opacities below 1/1 and gradings of pleural thickening below width ' $b$ ' and of calcification below grade 2 . In this way the problems caused by marginal abnormalities may be avoided and the more significant differences between readings brought into focus.

The first section of Table 4 shows the result of a strict comparison between the readings of the large and small films found to be positive at this standard level of abnormality, and it demonstrates a serious deficiency in the sensitivity of the small films. When lower categories and grades of abnormality are scored for the small films, and when readings by a minority of readers are added, this deficiency is progressively reduced to a point where agreement with the standard reading of the large film is close (section 4, Table 4). This resembles the situation in the screening procedure when all grades of abnormality recorded by any reader on the small films would lead to recall of the subjects for re-examination on large films. Despite the high recall rate $(20 \%)$ that would result from the application of the small film readings shown in section 4 of Table 4 , the false positive rate remains acceptably low (22 out of 549, or $4 \%$ ).

When the screening procedure by two readers in the survey of the total population is compared directly with reading to the standard level of abnormality (sections 5 and 6 of Table 4) a serious deficiency is demonstrated regardless of film size. For the small films, $36 \%$ of those with positive large films were screened as normal by both readers, but even for the large films $30 \%$ were screened as normal, although these were the same films that were subsequently read to the full classification.

For comparison, the repeatability of the reading of the triggers at this standard level of abnormality was such that $98.6 \%$ of the films read as positive the first time were also read as positive on the second occasion, and there was an overall agreement of $94.4 \%$. This high level of agreement was expected, as many of the triggers were chosen because they showed definite radiographic changes, and all were of good quality.

\section{AGREEMENT BETWEEN LARGE AND SMALL FILMS FOR TYPES AND GRADES OF ABNORMALITY}

Three characteristic features of asbestos-related abnormality have been considered in Table 5 . Pleural thickening, including both plaques and the diffuse type of uncalcified thickening, is classified by the width of the radiographic shadow, pleural calcification by grade, and small opacities, rounded or irregular, by category. In all cases only a majority reading by not less than three out of five readers has been used.

Taking any level of abnormality, agreement is best for calcification (17 of 29 , that is, $59 \%$ of results from large films were in accordance with those from small films) followed by pleural thickening $(55 \%)$, with a much poorer agreement for 
Table 5 Agreement between large and small films by type and extent of abnormality as recorded for 674 men by at least three of five readers

\begin{tabular}{|c|c|c|c|c|c|c|c|}
\hline \multirow[t]{2}{*}{ Extent of abnormality } & \multirow[t]{2}{*}{ Film size } & \multicolumn{2}{|c|}{ Pleural thickening } & \multicolumn{2}{|c|}{ Pleural calcification } & \multicolumn{2}{|c|}{ Small opacities } \\
\hline & & No. & $\%$ & No. & $\%$ & No. & $\%$ \\
\hline Any level & $\begin{array}{l}\text { Large } \\
\text { Small } \\
\text { Both }\end{array}$ & $\begin{array}{r}167 \\
114 \\
92\end{array}$ & $\begin{array}{l}24 \cdot 8 \\
16 \cdot 9 \\
13 \cdot 6\end{array}$ & $\begin{array}{l}29 \\
19 \\
17\end{array}$ & $\begin{array}{l}4 \cdot 3 \\
2 \cdot 8 \\
2 \cdot 5\end{array}$ & $\begin{array}{r}137 \\
66 \\
43\end{array}$ & $\begin{array}{r}20 \cdot 3 \\
9 \cdot 8 \\
6 \cdot 4\end{array}$ \\
\hline Standard level* & $\begin{array}{l}\text { Large } \\
\text { Small } \\
\text { Both }\end{array}$ & $\begin{array}{r}112 \\
78 \\
66\end{array}$ & $\begin{array}{r}16.6 \\
11.6 \\
9.8\end{array}$ & $\begin{array}{l}15 \\
14 \\
13\end{array}$ & $\begin{array}{l}2 \cdot 2 \\
2 \cdot 1 \\
1 \cdot 9\end{array}$ & $\begin{array}{r}14 \\
4 \\
1\end{array}$ & $\begin{array}{l}2 \cdot 1 \\
0 \cdot 6 \\
0 \cdot 1\end{array}$ \\
\hline Severe $†$ & $\begin{array}{l}\text { Large } \\
\text { Small } \\
\text { Both }\end{array}$ & $\begin{array}{l}71 \\
49 \\
37\end{array}$ & $\begin{array}{r}10 \cdot 5 \\
7 \cdot 3 \\
5 \cdot 5\end{array}$ & $\begin{array}{l}6 \\
4 \\
4\end{array}$ & $\begin{array}{l}0.9 \\
0.6 \\
0.6\end{array}$ & $\begin{array}{l}1 \\
0 \\
0\end{array}$ & $\begin{array}{l}0.1 \\
0.0 \\
0.0\end{array}$ \\
\hline
\end{tabular}

*Standard level is defined as: width $b$ or more for pleural thickening; grade 2 or more for pleural calcification; category $1 / 1$ or more for small opacities.

† Severe is defined as: width c for pleural thickening; grade 3 for pleural calcification; category $2 / 1$ or more for small opacities.

small opacities $(31 \%)$. If only the more extensive asbestos-related abnormalities are considered, the agreements between the readings of the two sizes of film are better for pleural calcification but rather worse for small opacities. For pleural thickening there appears to be a consistent trend for the width to be recorded as one size smaller on the small films.

More detailed analysis of the minority readings shows that small opacities are scored in over half the films, and these would be missed when only the majority opinion is used. It seems probable, therefore, that the additional information using all the readings would overcome the deficit of small opacities at least as well as it does the deficit of pleural abnormalities.

THE USE OF THE OBLIQUE VIEW

Oblique views of 1884 men in the sample population were assessed in the reading trial after the ILO U/C classification of the postero-anterior film had been recorded. A decision was taken about whether the oblique view increased, decreased, or made no difference to the certainty and to the grading of abnor- malities recorded on the postero-anterior view. This decision was recorded separately for pleural thickening, pleural calcification, and small opacities.

Table 6 shows the results of these decisions expressed as percentages of the total number of oblique views and based on the readings of at least three of the five readers. An increase in the grading of pleural thickening was observed in 50 cases and of pleural calcification in a further 14. In two more cases the grading of small opacities was increased. Of these 66 cases there were seven $(0.4 \%$ of all oblique views) in which the postero-anterior view had been read as entirely normal, and in this small proportion the oblique view was, therefore, the only indicator of abnormality, which was pleural thickening in all seven cases.

THE RELATION OF RADIOLOGICAL TO CLINICAL FINDINGS

The proportion of pleural abnormalities alone was: much higher in this survey than has been reported in other studies of asbestos-exposed workers, confirming the findings of Sheers and Templeton (1968) and Harries et al. (1972). Abnormal clinical

Table 6 Additional information from oblique view*

\begin{tabular}{|c|c|c|c|c|}
\hline \multirow[t]{2}{*}{ Feature } & \multirow[t]{2}{*}{ Assessment of information } & \multicolumn{3}{|l|}{ Abnormality } \\
\hline & & Pleural thickening & Pleural calcification & Small opacities \\
\hline Certainty of abnormality & $\begin{array}{l}\text { No change } \\
\text { Increased } \\
\text { Decreased }\end{array}$ & $\begin{array}{r}93.4 \% \\
6.2 \% \\
0.4 \%\end{array}$ & $\begin{array}{l}98.9 \% \\
1.0 \% \\
0.0\end{array}$ & $\begin{array}{r}97.5 \% \\
1.8 \% \\
0.2 \%\end{array}$ \\
\hline Level of abnormality & $\begin{array}{l}\text { No change } \\
\text { Increased } \\
\text { Decreased }\end{array}$ & $\begin{array}{c}97.2 \% \\
2.7 \% \\
0.05 \%\end{array}$ & $\begin{array}{l}99.3 \% \\
0.7 \% \\
0.0\end{array}$ & $\begin{array}{r}99.7 \% \\
0.1 \% \\
0.05 \%\end{array}$ \\
\hline$N=1884$ & & & & \\
\hline
\end{tabular}

*Agreement between at least three of five readers on the additional information available from the oblique view. 
findings are more relevant to the diagnosis of parenchymal fibrosis and could therefore influence only a small proportion of the results. The combination of persistent basal rales and a gas transfer factor reduced below $75 \%$ of the predicted value was observed in six cases, of which two were attributable to other diseases unrelated to asbestos. The remaining four were all indentified by the ILO U/C readings of the films, but one was missed on the small film in the screening procedure.

The other asbestos-related abnormalities were all pleural, nine being the diffuse type of pleural fibrosis and the remaining 79 being plaques. In most of these cases the diagnosis was essentially radiological, subject to confirmation from the occupational and past medical history. No case of diffuse pleural fibrosis was missed in the ILO U/C readings. One of the plaques was read as normal in all ILO U/C readings; three were missed on the large film readings only, and a further eight were missed on the small film readings. All these were small pleural plaques of little clinical significance. By comparison, 25 pleural abnormalities were missed on the small films in the screening procedure, one being a case of diffuse pleural thickening and the others pleural plaques.

FILM QUALITY

Variation in film quality was only to be expected in examinations spread over three years and involving two different radiographic techniques. Small and large films were compared for overall quality, movement, position, and definition of parenchyma and pleura separately (Table 7).

Table 7 Film quality, averaged for the five readers

\begin{tabular}{lcc}
\hline Quality & Large films & Small films \\
\hline Overall quality acceptable & $73 \%$ & $79 \%$ \\
Movement & $2 \%$ & $1 \%$ \\
Positioning imperfect & $1 \%$ & $20 \%$ \\
$\begin{array}{l}\text { Satisfactory definition } \\
\quad \text { Parenchyma }\end{array}$ & $81 \%$ & $87 \%$ \\
Pleura & $80 \%$ & $82 \%$ \\
\hline
\end{tabular}

The quality of the large films was not as good as that which could be achieved with more modern equipment, and these films were faulted rather more frequently for defects in overall quality and for difficulty in seeing detail in either parenchyma or pleura. This is partly a reflection of the greater ease of decision-making on the small films, because of the reduction in the total available information. The built-in fixed grid on the camera also reduces the problems arising from chest wall scatter. Exposure and processing faults seemed infrequent but one batch of small films suffered from faulty alignment. Movement was often not recorded, and the effects of this fault were more consistently noted under the heading of loss of parenchymal detail.

Positioning faults in small films were frequently recorded under the heading of 'cut bases' and resulted from a variable standard of positioning technique coupled with the difficulty caused by the shorter tube-screen distance on the Odelca camera. The format of the $100 \mathrm{~mm}$ film with its curved corners tends to produce this fault with heavily built subjects.

The large films were all $400 \mathrm{~mm} \times 400 \mathrm{~mm}$, which has been shown to lead to a considerable reduction in the proportion of films with loss of detail caused by poor positioning of the subject (Audsley et al., 1970). However, the image screen for miniature radiology is also $400 \mathrm{~mm} \times 400 \mathrm{~mm}$ so that there is a definite need to improve positioning when using small films, particularly when basal disease may be expected. This positioning could be improved by lowering the centring point and cancelling the tube angulation at the risk of some loss of detail at the apices.

\section{Discussion}

\section{READING METHODS}

The reading trial provides a basis for comparing the use of the ILO U/C classification with a simpler screening classification and also for evaluating trigger films and oblique views. It has been assumed in the discussion that immediate film reading for urgent clinical purposes has been completed as the first requirement.

Observer variation continues to present a considerable problem and has to be borne in mind when considering the results of film reading, even though variation in this trial was certainly no greater than that in other similar trials. This is the first occasion on which an attempt has been made to reduce variation by using trigger films. All readers agreed that the immediate feedback of information from the readings of these films helped to maintain a consistent reading level and reassured the reader that his opinion was not changing with time.

The comparison between reading methods shows that the discipline imposed by the use of the detailed ILO U/C classification and the advantage of direct comparison with films from a standard set are essential to the maintenance of consistently good standards. This is emphasised by the deficiency in the detection of abnormalities, which is nearly as great for large films as for small films, when the screening classification is used. 
Diagnostic sensitivity is closely related to the number of readers and it seems desirable to set three readers as a lower limit for an acceptable reading standard, with more if possible, in accordance with the report by Weill and Jones (1975).

Our choice of batch size and number of sessions per day seemed to be optimal, with fatigue detectable in the reader but not in his readings.

The additional information provided by the oblique view is slight and almost entirely limited to pleural thickening. For the best assessment of an individual with a possible abnormality the oblique views are necessary, but as a method for the detection of abnormalities in large-scale surveys the use of these views cannot be justified.

Film quality has an important influence on the results of reading, and could have been improved in this survey. Economies which might be gained by raising the examination rate or by lowering the technical staffing standards are likely to cause loss of significant information and may lead to a higher recall rate after screening examinations on small films. Developments in exposure control should be exploited in order to achieve the consistency which is so desirable in surveys of large groups and in serial examinations of individuals.

\section{CHOICE OF FILM SIZE}

The choice of small films for a survey of this size is influenced mainly by the lower costs and, to a lesser degree, by the easier handling of large numbers. Against these advantages must be set the lower diagnostic sensitivity, the higher radiation dose, and the need for a recall procedure.

If a majority reading of significant asbestosrelated change in a large film is set as the standard for radiographic abnormality, then even with five readers using the ILO U/C classification the deficiency when small films are used can be made good only by considering any abnormality recorded by any reader as the standard for recall. This level of sensitivity may be adequate for the purpose of comparing prevalence and attack rates within a given population, but is unlikely to be suitable for comparison with other studies and should be questioned when applied to the detection of individual abnormalities of possible clinical significance. In practice, very few clinical abnormalities were undetected by the ILO U/C readings and these were of little significance whereas, when the screening classification was used with small films, the number undetected was not only greater but included cases of more serious clinical significance.

The skin radiation dose from the small film exposure is higher than has been widely assumed. The average dose is equivalent to a total body radi- ation which would fall within the variations of natural background radiation and any risk resulting would be negligible (British Institute of Radiology, 1975). The upper part of the dose range (0.25-0.315 rem) comes into a higher category, but remains well below the limit set for members of the public within a period of one year (International Commission on Radiological Protection, 1966).

The lower costs of the small film examination result mainly from time-saving by automatic film changing. Large film units are now being developed with similar facilities and, when coupled to an automatic film processor, would eliminate most of this cost advantage. Staffing levels and examination rates would be similar, so that only the lower initial capital outlay and lower running costs for materials would remain to influence the choice of radiographic equipment.

The question of any form of compromise in radiographic technique does not arise in the clinical examination where the best available information from all sources would be used. Similarly, in the examination of a small group of workers known to have been at serious risk and where a high abnormality rate can be expected, no lowering of radiographic standards would be acceptable, and a clinical examination should not be omitted.

For large groups of workers, where the cost of a radiographic survey may impose restraints on surveillance, a case can be made for the use of small films provided that the asbestos-related abnormality rate is likely to be less than $5 \%$. Experience in the main survey suggests that the total recall rate for all reasons would not then exceed $15 \%$ and, at this level, the economy is substantial. In this particular epidemiological situation the diagnostic sensitivity of the small film is adequate provided that the standard of reading is sufficiently high.

\section{References}

Ashford, J. R., and Enterline, P. E. (1966). Radiologic classification of the pneumoconioses. Archives of Environmental Health, 12, 314-330.

Audsley, W. P., Latham, S. M., and Rossiter, C. E. (1970). Film sizes for radiography of the chest. Radiography, 36, 70-72.

British Institute of Radiology (1975). Irradiation of Human Subjects for Medical Research. British Institute of Radiology Bulletin No. 2, 1, 4. BIR: London.

Harries, P. G., Mackenzie, F. A. F., Sheers, G., Kemp, J. H., Oliver, T. P., and Wright, D. S. (1972). Radiological survey of men exposed to asbestos in naval dockyards. British Journal of Industrial Medicine, 29, 274-279.

Harries, P. G., Rossiter, C. E., and Coles, R. M. (1976). Royal Naval Dockyards Asbestosis Research Project. Royal Navy Clinical Research Working Party Report 1/76. Institute of Naval Medicine: Alverstoke, Gosport. 
International Commission on Radiological Protection (1966) Recommendations of the International Commission on Radiological Protection (adopted September 17, 1965). ICRP Publication 9. Pergamon Press: Oxford.

International Labour Office (1972). The ILO U/C International Classification of Radiographs of the Pneumoconioses, 1971. Occupational Safety and Health Series No. 22 (revised). ILO: Geneva.

Mackenzie, F. A. F., and Harries, P. G. (1970). Changing attitudes to the diagnosis of asbestos disease. Journal of the Roval Naval Medical Service, 56, 116-123.

Rossiter, C. E. (1972). Initial repeatability trials of the UICC/Cincinnati classification of the radiographic appearances of pneumoconiosis. British Journal of Industrial Medicine, 29, 407-419.

Sheers, G., and Templeton, A. R. (1968). Effects of asbestos in dockyard workers. British Medica! Journal, 3, 574-579.

Weill, H., and Jones, R. (Editors) (1975). The chest roentgenogram as an epidemiologic tool. Report of Workshop. Archives of Environmental Health, 30, 435-439. 